\title{
Pulmonary Embolism presenting as Syncope
}

\author{
Dipak Mall ${ }^{1}$, Yang Shaning ${ }^{1}$ \\ ${ }^{1}$ Department of Cardiology, The First Affiliated Hospital of Yangtze University, Jingzhou 434000, Hubei, China
}

\section{Citation}

Dipak Mall. Pulmonary Embolism presenting as Syncope. Nepalese Heart Journal 2015; 12 (1): $37-41$

\section{Key words}

Myocardial infarction; Pulmonary embolism; Syncope

\section{ABSTRACT}

The diagnosis of Pulmonary embolism can easily be missed if it is not considered as one of the major differential diagnosis in a case of syncope without chest pain. We describe a case of a 74years old female with pulmonary embolism induced syncope, which highlights one of the difficulties in diagnosing pulmonary embolism. In a patient presenting in syncope without chest pain but raised troponin, the possibility of pulmonary embolism should also be considered if it does not fit with myocardial infarction. Otherwise, the diagnosis can be easily missed and patients may not receive appropriate treatment resulting in increased mortality. Pulmonary embolism should be considered in the differential diagnosis of every syncopal event in Emergency department and Cardiac care units.

\section{INTRODUCTION}

Recognized venous thromboembolism (pulmonary embolism and deep venous thrombosis) is responsible formore than 250,000 hospitalizations and approximately 50,000 deaths per year in the United States. Because it is difficult to diagnose, the true incidence of pulmonary embolism is unknown, but it is estimated that approximately 650,000 cases occur annually. ${ }^{1}$

The incidence of pulmonary embolism (PE) differs among different countries depending upon the accuracy of diagnosis and the new medical diagnostic approach. Despite the possibility of high incidence of pulmonary embolism, its diagnosis continues to be difficult, primarily because of the vague presentation. Conversly, syncope is a relatively easy clinical symptom to detect, but has varied etiologies that lead to a documented cause in only $58 \%$ of syncopal events. Syncope as the presenting symptom of pulmonary embolism has proven to be a difficult clinical correlation to make. ${ }^{2}$ Syncope is the presenting symptom in $6 \%$ patients with Pulmonary embolism. ${ }^{3}$

\section{CASE PRESENTATION}

A 74 year old female patient presented to our department after she had two syncopal episode at home. In Coronary care unit (CCU), she was also diaphoretic and mild dyspneic but had no associated chest pain, and palpitation. No seizures were witnessed. No history of fever, abdominal

\section{Corresponding Author}

\section{Dipak Mall}

Department of Cardiology

The First Affiliated Hospital of Yangtze University

Jingzhou 434000, Hubei, China

E-mail:drdmalla@hotmail.com 
pain, productive cough, decreasing level of consciousness, flank pain and hemoptysis was given.

She was admitted to our hospital eight months ago for dull chest pain and throat discomfort. She was diagnosed as chronic stable angina eight months back. Computer tomography angiography revealed $70 \%$ diffuse stenosis of left anterior descending artery.

Her vital signs upon arrival in CCU were; Temp: $36.7 \mathrm{C}$, blood pressure 125/72 $\mathrm{mmHg}$, heart rate $102 \mathrm{bpm}$ regular, respiratory rate was 30breaths/minute. Arterial blood gas analysis revealed moderate hypoxia $\mathrm{PO} 2=74 \mathrm{mmHg}$, PCO2 $44 \mathrm{mmHg}$. Examination of head and neck was normal. The chest wall examination with cardiovascular and respiratory system was normal.

Level of Serum Electrolytes, glucose, blood urea, creatinine and blood cell count were within normal limits. No dynamic cardiac enzymes were elevated except Troponin level being $0.003 \mathrm{ng} / \mathrm{ml}$. Chest x-ray was normal. A transthoracic echocardiogram $(\mathrm{ECHO})$ revelaed normal left ventricle function without atrial septal defect or a ventricular septal defect. No signs of right ventricular dilatation were seen. An electrocardiograph (ECG) shows regular sinus tachycardia rhythm but two episodes of nonsustained ventricular tachycardia was seen on ECG monitor.

In order to find out a cause of syncope we did a bed side doppler scan of the lower limb, which revealed an acute deep vein thrombosis (DVT) in the right lower limb on right posterior tibia vein thrombosis which gave us a clue to perform immediate computer tomography pulmonary angiogram (CTPA), that shows right sided pulmonary embolism on right pulmonary artery(Figure 1) and right lower lobe artery on apical segment of the right lower lobe. (Figure 2)

The patient was started with Warfarin following initial low molecular weight Heparin. Once the patient was stable, a inferior vena cave filter (IVC) was placed below the renal vein aimed to decrease the risk of recurrence of venous thrombus embolism (VTE).

\section{DISCUSSION}

PE may escape prompt diagnosis since the clinical signs and symptoms are non-specific. 3

When the clinical presentation raises the suspicion of $\mathrm{PE}$ in an individual patient, it should prompt further objective testing. In most patients, PE is suspected on the basis of dyspnoea, chest pain, pre-syncope or syncope, and/or haemoptysis. ${ }^{4.5 .6}$

Syncope is infrequent, but may occur regardless of the presence of haemodynamic instability.7 In more severe cases, cyanosis, syncope and circulatory instability occur, and sometimes peripheral edema may be present. ${ }^{8}$

Syncope in the setting of pulmonary embolism can be the result of three possible mechanisms. First, greater than $50 \%$ occlusion of the pulmonary vascular tree causes right ventricular failure and impaired left ventricular filling, leading to a reduction in cardiac output, arterial hypotension, reduced cerebral blood flow, and ultimately syncope. The second mechanism of syncope associated with pulmonary embolism is the appearance of arrhythmias associated with right ventricular overload. In the third mechanism, the embolism can trigger a vasovagal reflex that leads to neurogenic syncope. However, the contribution of hypoxemia secondary to ventilation or perfusion abnormalities must also be considered and may play an important role in the development of syncope. Moreover, acute pulmonary hypertension may also lead to rightto-left flow across a patent foramen ovale, and thus exacerbate hypoxemia. ${ }^{9.10}$

The clinician should seek the following clues to the diagnosis of pulmonary embolism in patients who have had a syncopal episode: (a) hypotension and tachycardia (b) acute corpulmonale according to electrocardiogram criteria and (c) other signs and 
symptoms indicative of pulmonary embolism. The presence of any of these findings without other obvious causes of syncope should lead to further work-up, including arterial blood gas analysis, ventilation-perfusion scanning, lower extremity duplex sonogram, echocardiography, multislice computed tomography pulmonary artery and coronary angiography to rule out coronary heart disease. ${ }^{11,12}$

Nowadays, lower limb compression ultrasonography (CUS)has largely replaced venography for diagnosing DVT. CUS has a sensitivity $>90 \%$ and a specificity of approximately $95 \%$ for symptomatic DVT. ${ }^{13.14}$ CUS shows a DVT in $30-50 \%$ of patients with PE. ${ }^{15,16,17}$

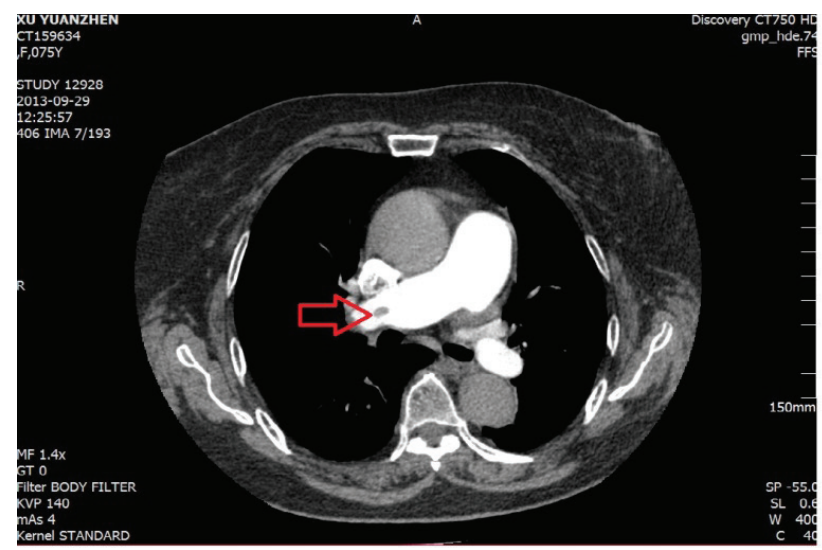

Figure 1.The arrow shows embolism on Right pulmonary artery

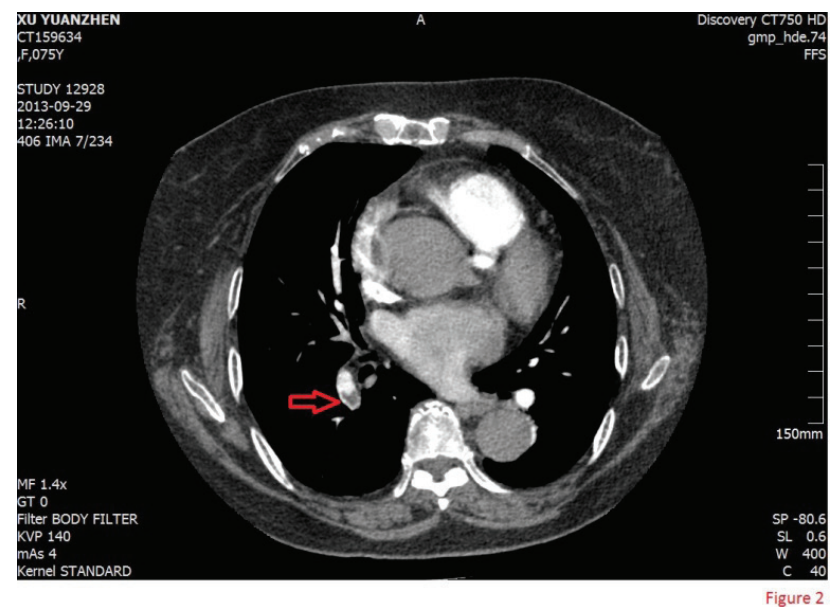

Figure 2. The arrow shows embolism right lower lobe artery
Venous filters are usually placed in the infrarenal portion of the IVC.Venous filters are indicated in patients with acute PE who have absolute contraindications to anticoagulant drugs, and in patients with objectively confirmed recurrent PE despite adequate anticoagulation treatment. Observational studies suggest that insertion of a venous filter might reduce PE-related mortality rates in the acute phase, ${ }^{18,19}$ benefit possibly coming at the cost of an increased risk of recurrence of VTE. ${ }^{19}$

As in our case the old lady presented to us in syncope with mild dyspnoea and tachypnoea but without clinical features such as chest pain, palpitation and haemoptysis. It was very hard for us to think of PE on initial management and considering her past medical history the case was more likely to be diagnosed as acute myocardial infarction, rather than pulmonary embolism

The only supporting mode of diagnosis for pulmonary embolism to our patient was prompt doppler scan of the lower extremities, as it was available bedside, with findings of deep vein thrombosis in the right posterior tibia vein and was confirmed by CTPA with right sided pulmonary embolism.

In our patient, inferior vena cava filter placement was aimed to decrease the risk of recurrence of VTE.

\section{CONCLUSION}

Pulmonary embolism presenting with syncope is difficult to diagnose. PE may escape prompt diagnosis since the clinical signs and symptoms are non-specific as stated above on the discussion that syncope is a relatively easy clinical symptom to detect, but has varied etiologies that lead to a documented cause in only $58 \%$ of syncopal events and syncope is the presenting symptom in only $6 \%$ patients with pulmonary embolism. We presented a rare case in which pulmonary 
embolism induced syncope was presented with mild dyspnoea and tachycardia but not with chest pain, cough and heamoptysis and no changes were seen on ECG and ECHO.

We would like to give message that physicians must be aware with patients who have syncope, because this symptom may be a 'forgotten sign' of life-threatening pulmonary embolism. This case highlights that pulmonary embolism should be considered in the differential diagnosis of every syncopal event in Emergency department and Cardiac care units.

\section{REFERENCES}

1. Wolfe TR, Allen TL: Syncope as an emergency department presentation of pulmonary embolism. J Emerg Med 1998, 16:27-31

2. Manolis AS, Linzer M, Estes M III: Syncope: current diagnostic evaluation and management. Ann Intern Med 1990, 112:850-863

3. Pollack CV, Schreiber D, Goldhaber SZ, Slattery D, Fanikos J, O’Neil BJ, Thompson JR, Hiestand B, Briese BA, Pendleton RC, Miller CD, Kline JA. Clinical characteristics, management, and outcomes of patients diagnosed with acute pulmonary embolism in the emergency department: initial report ofEMPEROR(Multicenter Emergency Medicine PulmonaryEmbolism in the RealWorld Registry). J Am Coll Cardiol 2011;57(6):700-706.

4. Miniati M, Prediletto R, Formichi B, Marini C, Di Ricco G, Tonelli L, Allescia G, Pistolesi M. Accuracy of clinical assessment in the diagnosis of pulmonary embolism. Am J Respir Crit Care Med 1999;159(3):864-871.

5. Pollack CV, Schreiber D, Goldhaber SZ, Slattery D, Fanikos J, O’Neil BJ, Thompson JR, Hiestand B, Briese BA, Pendleton RC, Miller CD, Kline JA. Clinical characteristics, management, and outcomes of patients diagnosed with acute pulmonary embolism in the emergency department: initial report ofEMPEROR(Multicenter Emergency Medicine PulmonaryEmbolism in the RealWorld Registry). J Am Coll Cardiol 2011;57(6):700-706.

6. Wells PS, Ginsberg JS, Anderson DR, Kearon C, Gent M, Turpie AG, Bormanis J, Weitz J, Chamberlain M, Bowie D, Barnes D, Hirsh J. Use of a clinical model for safe management of patients with suspected pulmonary embolism. Ann Intern Med 1998;129(12):997-1005.

7. Thames MD, Alpert JS, Dalen JE. Syncope in patients with pulmonary embolism. JAMA 1977;238(23):2509-2511.

8. Othman AAA, Tohamy AM and Hassan AKM. Pulmonary embolism presented by syncope in a low-risk patient: a case report [v1; ref status: approved with reservations 2, F1000Research 2013, 2:257

9. Thames MD, Alpert JS, Dalen JE: Syncope in patients with pulmonary embolism. JAMA 1977, 238:2509-2511 
10. Simpson RJ, Podolak R, Mangano CA Jr, Foster JR, Dalldorf FG: Vagal syncope during recurrent pulmonary embolism. JAMA 1983, 249:390-393

11. Varon J, Fromm RE: Syncope: the forgotten sign of pulmonary embolism. J Emerg Med 1998, 16:117-118.

12. Soloff LA, Rodman T: Acute pulmonary embolism. Am Heart J 1967, 74:629-647.

13. Kearon C, Ginsberg JS, Hirsh J. The role of venous ultrasonography in the diagnosis of suspected deep venous thrombosis and pulmonary embolism. Ann Intern Med 1998;129(12):1044-1049.

14. Perrier A, Bounameaux H. Ultrasonography of leg veins in patients suspected of having pulmonary embolism. Ann Intern Med 1998;128(3):243-245.

15. Righini M, Le Gal G, Aujesky D, Roy PM, Sanchez O, Verschuren F, Rutschmann O, Nonent M, Cornuz J, Thys F, Le Manach CP, Revel MP, Poletti PA, Meyer G, Mottier D, Perneger T, Bounameaux H, Perrier A. Diagnosis of pulmonary embolism by multidetector $\mathrm{CT}$ alone or combined with venous ultrasonography of the leg: a randomised non-inferiority trial. Lancet 2008;371(9621):1343-1352.

16. Perrier A, Bounameaux H. Ultrasonography of leg veins in patients suspected of having pulmonary embolism. Ann Intern Med 1998;128(3):243-245.

17. Righini M, Le GG, Aujesky D, Roy PM, Sanchez O, Verschuren F, Kossovsky M, Bressollette L, Meyer G, Perrier A, Bounameaux H. Complete venous ultrasound in outpatients with suspected pulmonary embolism. J Thromb Haemost 2009;7(3): 406-412.

18. Stein PD, Matta F, Keyes DC, Willyerd GL. Impact of vena cava filters on in-hospital case fatality rate from pulmonary embolism. Am J Med 2012;125(5):478-484.

19. Muriel A, Jime'nez D, Aujesky D, Bertoletti L, Decousus H, Laporte S, Mismetti P, Muñoz FJ, Yusen R, Monreal M; RIETE Investigators. Survival effects of inferior vena cava filter in patients with acute symptomatic venous thromboembolism and a significant bleeding risk. J Am Coll Cardiol 2014;63(16):1675-1683.

20. Kapoor WN: Evaluation and management of patients with syncope. J Am Med Assoc 1992, 268:2553-2560 